\title{
USING OF AEROGEL TO IMPROVE THERMAL INSULATING PROPERTIES OF WINDOWS
}

\author{
Denisa VALACHOVA ${ }^{1, *}$, Nada ZDRAZILOVA ${ }^{1}$, Vladan PANOVEC ${ }^{1}$, \\ Iveta SKOTNICOVA ${ }^{1}$
}

${ }^{1}$ Department of Building Environment and Building Services, Faculty of Civil Engineering, VŠB Technical University of Ostrava, 17. listopadu 15/2172, 70833 Ostrava, Czech Republic.

corresponding author: denisa.donova@vsb.cz.

\section{Abstract}

For the best possible thermal-technical properties of building structures it is necessary to use materials with very low thermal conductivity. Due to the increasing thermal-technical requirements for building structures, the insulating materials are developed. One of the modern thermal insulating materials is so-called aerogel. Unfortunately, this material is not used in the field of external thermal insulation composite systems because of its price and its properties. The aim of this paper is to present possibilities of using this insulating material in the civil engineering - specifically a usage of aerogel in the production of windows.
\end{abstract}

\section{Keywords:}

Insulating materials;

Aerogel;

Window;

Window frame;

Building envelope.

\section{Introduction}

Due to the increasing thermal-technical requirements for building structures, new insulation materials are developed. One of these materials is a thermal insulation called aerogel. It is a material with a very low thermal conductivity [1]. Thanks to this, it is the material which is suitable for a use in a civil engineering to reduce heat losses of buildings. The heat losses are affected by thermal-technical properties of a building envelope. The building envelope consists of structures, which are located on a boundary of a heated area of a building. New buildings are designed so that the thermal coupling coefficient of these structures is as low as possible [2]. In the case of non-transparent structures, this is usually ensured by using of the thermal insulator as a part of the structure. However, windows are the most problematic parts of the building envelope. The transmission heat loss coefficient ( $U$-value) of windows is much higher than the $U$-value of the non-transparent structures. The $U$-value of the nontransparent structures of new buildings is commonly in the range of $0.1-0.2 \mathrm{~W} \cdot \mathrm{m}^{-2} \cdot \mathrm{K}^{-1}$. The $U$-value of new windows is in the range of $0.5-1.2 \mathrm{~W} \cdot \mathrm{m}^{-2} \cdot \mathrm{K}^{-1}$. The possible improvements of the thermaltechnical properties of windows are already relatively limited. One of the possibilities to improve these properties is a use of the aerogel [3 - 6] in the structure of windows. The aim of the research is a thermal technical assessment of a window frame with inserted aerogel insulation. This window frame was compared with common window frames. The main benefit of the research is the possibility of using of the window frame with inserted aerogel insulation to improving of the thermal technical parameters of windows.

\section{Aerogel as an insulating material}

The aerogel is a solid material, based on silicon, with the lowest possible density $[7,8]$. It contains more than $95 \%$ of air; the rest is silica $\left(\mathrm{SiO}_{2}\right.$ - Silicon dioxide). The aerogel is made by drying of liquid gel due to the preservation of its shape. It is done by so-called supercritical drying method. The silica gel is dried at high pressure and temperature with the addition of catalysts. The aerogel was developed in the '30s of the 20th century at the Stanford University. However, the production of aerogel was very problematic at that time. Its production became more effective during a space research. Since that time, aerogel also started to be used in other research areas. The thermal conductivity coefficient of aerogel is extremely low, it is in the range of 0.013 to $0.020 \mathrm{~W} \cdot \mathrm{m}^{-1} \cdot \mathrm{K}^{-1}[9]$. In comparison with the thermal conductivity coefficient of today commonly used thermal insulations, the thermal conductivity coefficient of aerogel is up to 3 times lower. For example, the thermal 
conductivity coefficient of frequently used modern EPS with addition of graphite (called grey EPS) is $0.031 \mathrm{~W} \cdot \mathrm{m}^{-1} \cdot \mathrm{K}^{-1}$. Besides of its excellent thermal insulation properties, the aerogel is also a nonflammable and a transparent material. The optical transmittance of aerogel is in the range of 0.85 to 0.95 depending on its thickness [10]. Therefore, it is possible to use this material in a structure of transparent facades [11].

\section{Using of aerogel in the area of the window production}

The main aim of this research was to find a way how to use the aerogel in a windows production, and thereby to improve the thermal insulation properties of windows. As mentioned above, the aerogel is a material with a high value of the optical transmittance and also with the acceptable solar transmittance [12]. Therefore it allows a usage of this insulator as a part of a window glazing [13]. The aerogel can be also used as a part of a window frame. Thermal technical properties of windows depend on the construction solution of their components. The window transmission heat loss coefficient is determined by the thermal technical properties of a window glazing, a window frame and on a type of a spacer, which is located in a glazing joint between glazing panes. The $U$-value of windows is determined according to the standard CSN EN ISO 10077-1 "Thermal performance of windows, doors and shutters - Calculation of thermal transmittance - Part 1: General" according to Equation (1). Equation (1) shows that the $U$-value of windows depends on the $U$-value of a window glazing, on the $U$-value of a window frame and on the linear thermal transmittance of the glazing joint. It is evident from Fig. 1.

$U_{w}=\frac{A_{g} \cdot U_{g}+A_{f} \cdot U_{f}+\psi_{g} \cdot l_{g}}{A_{g}+A_{f}}$,

where: $U_{w}$ is the $U$-value of the window $\left(\mathrm{W} \cdot \mathrm{m}^{-2} \cdot \mathrm{K}^{-1}\right)$,

$A_{g}$ is an area of the window glazing $\left(\mathrm{m}^{2}\right)$,

$U_{g}$ is the $U$-value of the window glazing $\left(\mathrm{W} \cdot \mathrm{m}^{-2} \cdot \mathrm{K}^{-1}\right)$,

$A_{f}$ an area of the window frame $\left(\mathrm{m}^{2}\right)$,

$U_{f}$ is the $U$-value of the window frame $\left(\mathrm{W} \cdot \mathrm{m}^{-2} \cdot \mathrm{K}^{-1}\right)$,

$\psi_{g}$ is a linear thermal transmittance of the glazing joint $\left(\mathrm{W} \cdot \mathrm{m}^{-1} \cdot \mathrm{K}^{-1}\right)$,

$l_{g}$ is a length of the glazing joint $(\mathrm{m})$.

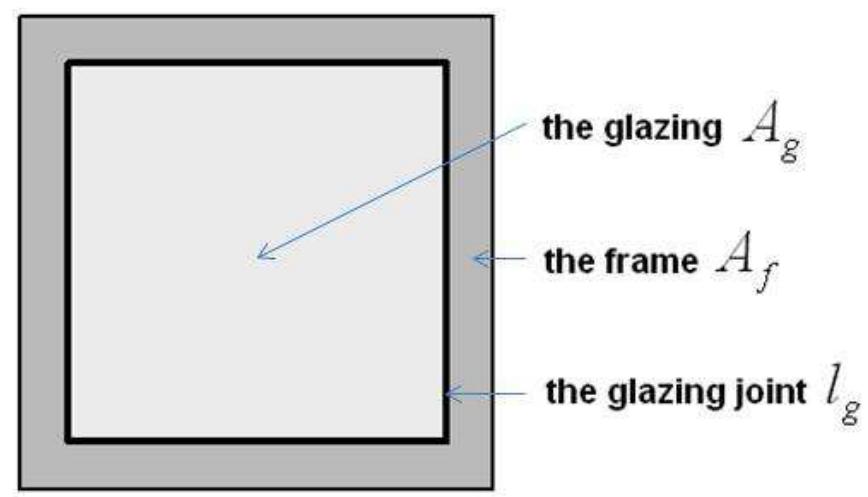

Fig.1: The schema of the window.

\subsection{Properties of the window glazing}

Thermal insulating properties of the window glazing are determined by its type. Multiple glazing is commonly used to increase its thermal resistance. Due to the more strict requirements for the energy efficiency of buildings, double-glazing systems [14] are replaced by triple-glazing systems. The transmission heat loss coefficient ( $U$-value) of a window glazing is primary determined by a thickness of an air gap between glass panes and also by a type of its filling. For increasing the thermal resistance of the glazing, a metal coating of an internal glass pane is also used. However, the coating causes a significant reduction of the solar transmittance of windows - a reduction of a so-called solar factor $g$. Due to the reduction of the solar factor $g$, solar heat gains are lower. This can have a 
negative impact to a total heat balance of building in winter. The number of glasses and thickness of the air gap significantly affects the $U$-value of the window glazing. It is worth mentioning that the type of the gap filling is very important. Previously used air gaps were replaced by the gaps filled by inert gases to improve a thermal resistance of the glazing. It is most often argon or krypton. The thermal conductivity of these gases is very low in comparison with the air. Due to this fact, the $U$-value of this type of glazing is significantly lower. For example, in double-glazing systems, the $U$-value of glazing may be two times lower than the $U$-value of a glazing filled by air. However, a possible leakage of inert gases from the space between the glass panes during aging of windows is a big disadvantage [15]. The maximum gas volume, that can escape, is specified in the standard CSN EN 1279-3 "Glass in building - Insulating glass units - Part 5: Evaluation of conformity". The maximum leakage of gas is $1 \%$ of filling volume per one year. It is evident that there could be a gradual deterioration of thermal insulation properties of the window glazing. The leakage of gas may be often demonstrated by measurements.

It is possible to use excellent thermal insulating properties of aerogel by placing of aerogel to a gap between glasses. In comparison with a use of inert gas, the leakage of gas is not possible. Thus, the thermal insulation properties of windows are not deteriorating during a windows lifetime. Because the aerogel is almost transparent material, its usage as a part of glazing is possible. Unfortunately, the solar factor of the glazing is reduced. It is undesirable. It may be assumed, that the development of aerogel will increase its solar transmittance and then it would be more realistic to use aerogel as a part of glazing. Nowadays, the aerogel is slightly blue, which is undesirable in the case of windows. However, in the case of transparent facades it could be considered as a design element. In the window glazing production, it is not possible to expect any substantial improvements of thermal insulation properties. Also quadruple glazed windows are used. Unfortunately a production of such windows can be very expensive and inefficient, and there is also a problem with a weight of glazing and a reducing of solar transmittance. The $U$-value of this window glazing is about $0.5 \mathrm{~W} \cdot \mathrm{m}^{-2} \cdot \mathrm{K}^{-1}$. It is not possible to expect a significant improvement of thermal insulating properties of a window glazing.

\subsection{Properties of the window frame}

Thermal technical properties of windows are affected by properties of a window frame [16]. According to a type of a material, window frames can be divided into wood frames [17, 18], metal frames and now commonly used plastic frames. Thermal technical properties of the window frames depend on their structural design. For plastic frames, it is affected by number of air chambers, which the frame consists of [19]. The frames with large thickness and many chambers have better thermal insulating properties. Nowadays, the window frames with five to eight chambers are commonly used. It is important to realize that increasing of a frame depth is limited. The production of window frames with eight chambers is economically inefficient. So it is necessary to achieve better thermal insulating properties in another manner. It can be achieved for example by using of thermal insulating materials as a part of the window frame. For this purpose, materials such as EPS or PUR are used. Significant reduction of a thermal coupling coefficient of window frames is also possible through the using of special composite materials. Thanks to these materials it is not necessary to insert a steel reinforcement, which significantly improves a thermal coupling coefficient, into the frame. Unfortunately, the production of these window frames is also very expensive. Then, the price of this type of frames will be considerably worse.

\subsection{Window spacers}

Another important element of windows, which significantly affects the total transmission heat loss coefficient of windows, is a window spacer. It is a piece of a window frame, which is located between glass panes in the window glazing [20]. In past, the spacers were made of metal (aluminium or less thermal conductive stainless materials). The increasing thermal conductivity at the points of the spacer is the biggest problem of this type. For this reason, metal spacers are nowadays replaced by so-called warm spacers. Warm spacers are made from a combination of materials (steel and polycarbonate or of fiberglass). The fiberglass spacers are considered to be the most convenient ones. During the calculation of the transmission heat loss coefficient of the window according to the equation (1) an effect of spacers is reflected by a linear thermal coupling coefficient of the glazing joint. If the thermal conductivity of the spacer is high, the value of the linear thermal coupling coefficient of the glazing joint is high too. 


\section{Using of aerogel inside the window frame}

As mentioned above, to improve insulating properties of windows, thermal insulation materials are used as a part of the window frames. The insulation material is placed into individual chambers of the plastic frame. It is in this area that it is possible to use the aerogel. Window frames with aerogel are made by inserting of aerogel strips into the plastic profile of the frame using a special hook. The strips are prepared by cutting of the aerogel thermal insulation, which is normally supplied in the form of a roll. Due to very low thermal conductivity of aerogel, it is possible to assume a reduction of the $U$-value of the window frame. This theory was verified by numerical analysis (the Final Element Method). Many numerical models for different types of window frames were created by the software Area 2011. Frames with thickness of 70 to $110 \mathrm{~mm}$ were created to plastic frames (simulate fivechamber to eight-chamber). Also numerical models for a standard frame were performed, for a frame with an inserted thermal insulation and also for the composite frame without the reinforcement. Examples of eight-chamber plastic frame are shown in Fig. 2. It is evident that thermal insulation was placed into the first chambers and also into the chambers before reinforcements. The calculation was performed for several types of insulators - for EPS, EPS grey, PUR and aerogel. The thermal conductivity coefficient of these insulating materials is listed in Table 1. Table 2 shows the thickness and the number of chambers of created frames.

a)

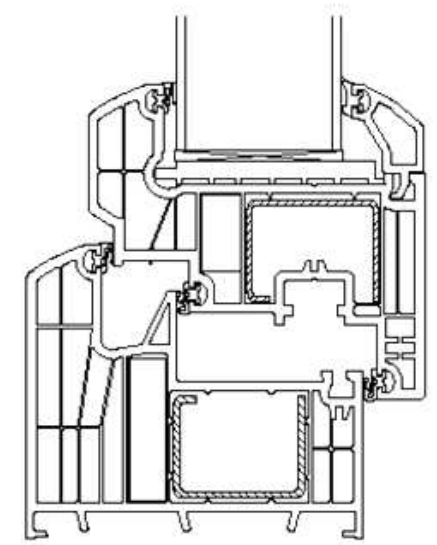

b)

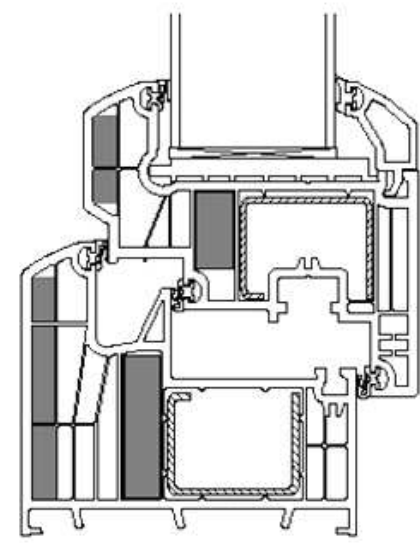

c)

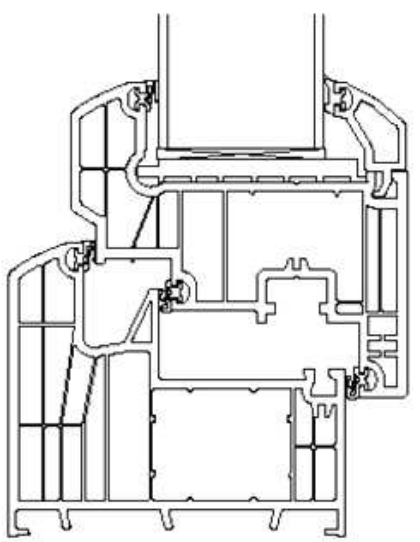

Fig. 2: Window frames: a) standard window frame, b) window frame with inserted thermal insulation, c) composite window frame without the reinforcement.

Table 1: Thermal insulating materials inserted in frames.

\begin{tabular}{|c|c|}
\hline Material & Thermal conductivity coefficient $\lambda_{\boldsymbol{u}}$ \\
\hline EPS & $0.039 \mathrm{~W} \cdot \mathrm{m}^{-1} \cdot \mathrm{K}^{-1}$ \\
\hline EPS Grey & $0.034 \mathrm{~W} \cdot \mathrm{m}^{-1} \cdot \mathrm{K}^{-1}$ \\
\hline PUR & $0.024 \mathrm{~W} \cdot \mathrm{m}^{-1} \cdot \mathrm{K}^{-1}$ \\
\hline Aerogel & $0.016 \mathrm{~W} \cdot \mathrm{m}^{-1} \cdot \mathrm{K}^{-1}$ \\
\hline
\end{tabular}

Table 2: Thickness of created frames.

\begin{tabular}{|c|c|}
\hline Number of chambers & Thickness $(\mathbf{m m})$ \\
\hline 5 & 70 \\
\hline 6 & 75 \\
\hline 6 & 80 \\
\hline 7 & 90 \\
\hline 7 & 95 \\
\hline 7 & 10 \\
\hline 7 & 110 \\
\hline
\end{tabular}




\subsection{The calculation of the $U$-value of window frames $U_{f}$}

To calculate the transmission heat loss coefficient of the window frame, it is necessary to know its linear thermal coupling coefficient. The linear thermal coupling coefficient was established by numerical calculation of two-dimension temperature field by software Area 2011. During calculation of the temperature area it is necessary to fulfil all required parameters of the computational model, these are given in the standard CSN EN ISO 10077-2 "Thermal performance of windows, doors and shutters - Calculation of thermal transmittance - Part 2: Numerical method for frames". For creating the computational model of the frame, it is important to replace the glazing by so-called thermal insulating panel. The thermal conductivity coefficient of the panel is $0.035 \mathrm{~W} \cdot \mathrm{m}^{-1} \cdot \mathrm{K}^{-1}$ and the thickness of the panel must be corresponding to the thickness of glazing. Computational model parameters are shown in Fig. 3. Then the $U$-value of the frame can be determined according to the standard CSN EN ISO 10077-2 by the equation (2).

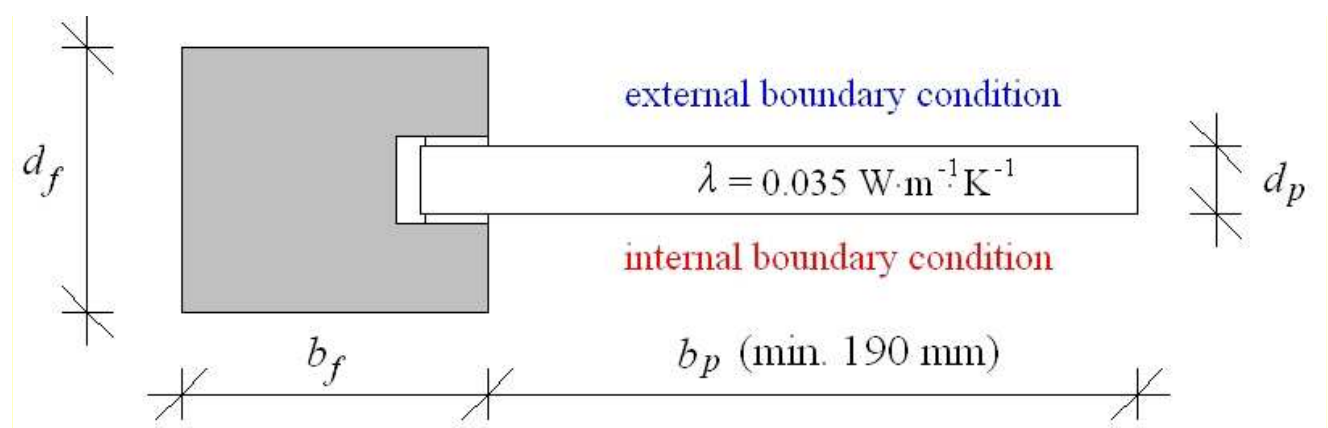

Fig. 3: Computational model parameters.

$$
U_{f}=\frac{\left(L_{2 D}-U_{p} \cdot b_{p}\right)}{b_{f}}
$$

where: $L_{2 D}$ is a linear thermal coupling coefficient of a frame fragment $\left(\mathrm{W} \cdot \mathrm{m}^{-1} \cdot \mathrm{K}^{-1}\right)$,

$U_{p}$ is a transmission heat loss coefficient of the thermal insulating panel $\left(\mathrm{W} \cdot \mathrm{m}^{-2} \cdot \mathrm{K}^{-1}\right)$,

$b_{p}$ is a width of the thermal insulating panel $(\mathrm{m})$,

$d_{p}$ is a thickness of the thermal insulating panel $(\mathrm{m}), d_{p}=d_{g}$ (a thickness the glazing $(\mathrm{m})$ ),

$b_{f}$ is a width of the frame $(\mathrm{m})$,

$d_{f}$ is a thickness of the frame $(\mathrm{m})$.

\subsection{The results of numerical calculation}

The results of the calculation are shown in Fig. 4. The graph shows an impact of the type of the frame to its transmission heat loss coefficient. Due to the results it is evident that the composite frames without the reinforcement have the best thermal insulating properties. However, the difference between these frames and frames with the reinforcement is more significant while using thinner frames. Then the difference is not so evident, and the production of composite frames is relatively uneconomic. The seven-chamber frame of thickness of $95 \mathrm{~mm}$ is very interesting. This frame has better thermal insulating parameters than the composite frame. This is mainly affected by the thermal conductivity of the air inside the frame, which depends on the dimensions of the chambers. The results show that the most appropriate case of using of the frame with inserted aerogel insulation is in the case of the window frame of thickness of $95 \mathrm{~mm}$. The window frame of this thickness is suitable to use the triple glazing. The combination of this frame and the triple glazing can achieve very good heatinsulating properties of windows. The advantage of the frame with the inserted aerogel is its excellent thermal insulation properties. The disadvantage of this frame is its demanding manufacturing and increase prices by $30 \%$ in comparison with the standard frame without insulation. 


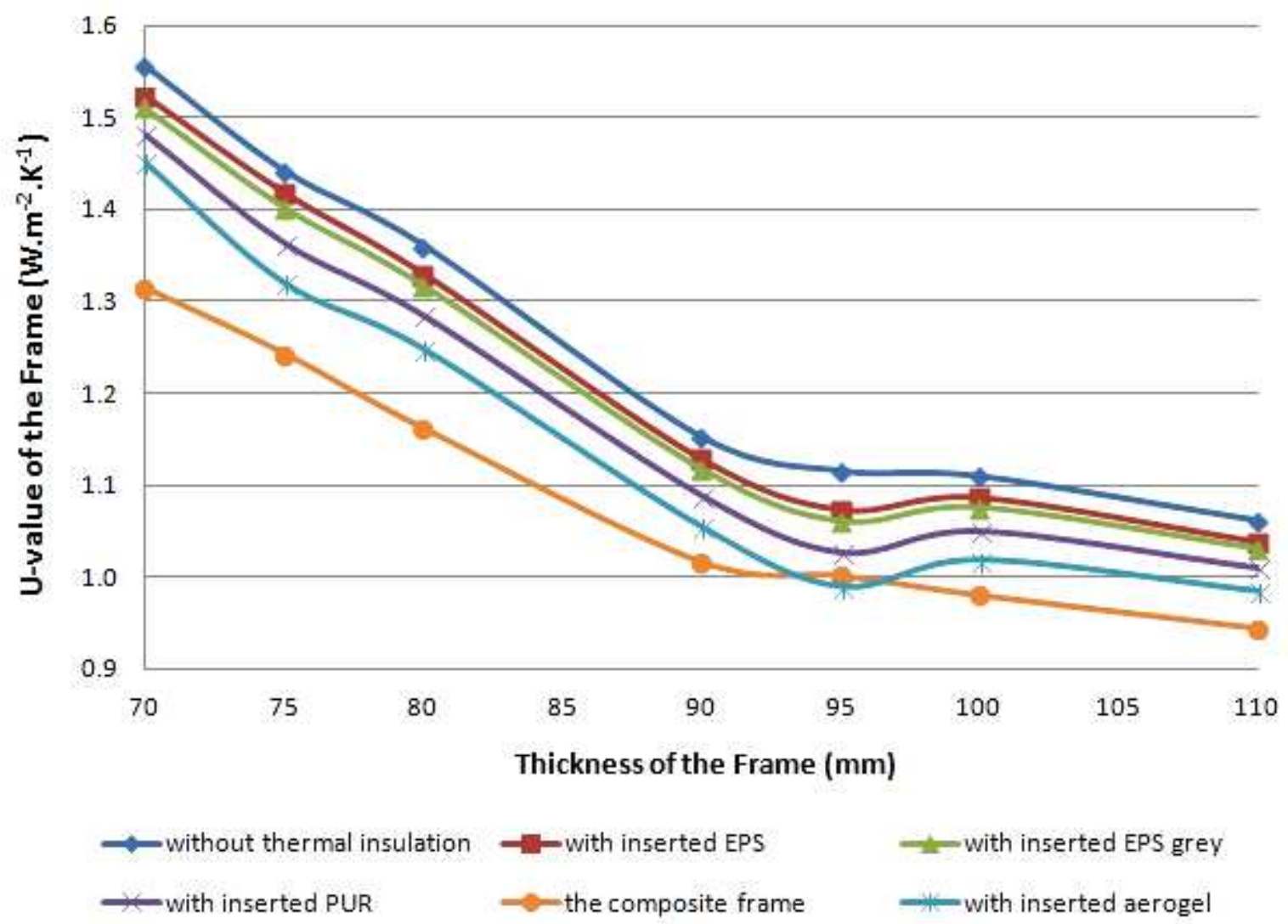

Fig. 4: The impact of type of the frame to its $U$-value.

\section{Total transmission heat loss coefficient of pane opening}

As mentioned above, the total heat transmission heat loss coefficient of pane opening is determined by kind of the glazing and the frame and also by the kind of a spacer. An effect of spacers is reflected by a linear thermal coupling coefficient of the glazing joint. For plastic windows, the value of linear thermal coupling coefficient of the glazing joint is usually from about $0.032 \mathrm{~W} \cdot \mathrm{m}^{-1} \cdot \mathrm{K}^{-1}$ (plastic spacers) to $0.080 \mathrm{~W} \cdot \mathrm{m}^{-1} \cdot \mathrm{K}^{-1}$ (aluminous spacers). It, indeed, depends on the spacer material. To compare the effect of the parts of windows to the total heat loss coefficient, the $U$-values of windows with different kind of the frame, glazing and spacer were calculated. The $U$-values of windows with standard size $1200 \times 1500 \mathrm{~mm}$ were calculated according to the equation (1). The $U$-values of windows with frame thickness $95 \mathrm{~mm}$ are presented. This thickness of the frame is the most suitable according to previous results of calculations presented in Fig. 4.

The calculation was made for all kinds of the window frame, which were presented in the previous chapter, and for four kinds of glazing. The results of the calculation are presented in Tables 3 and 4 . The results indicate the range of the $U$-values depending on the kind of spacer, it means for linear thermal coupling coefficient of the glazing joint in the range of 0.032 to $0.064 \mathrm{~W} \cdot \mathrm{m}^{-1} \cdot \mathrm{K}^{-1}$. The results show that the $U$-value of windows is mainly influenced by a kind of glazing. Significant differences are also achieved by different kind of spacers. The difference is almost $0.1 \mathrm{~W} \cdot \mathrm{m}^{-2} \cdot \mathrm{K}^{-1}$. The difference influenced by kind of the frame is only about $0.04 \mathrm{~W} \cdot \mathrm{m}^{-2} \cdot \mathrm{K}^{-1}$. The results also show that the $U$-values of windows with the frame with inserted aerogel are similar or even better than the $U$-values of windows with the composite frame. 
Table 3: $U$-values of triple-glazed windows and of double-glazed windows.

\begin{tabular}{|c|c|c|c|c|}
\hline \multirow{2}{*}{ Kind of the frame } & \multicolumn{4}{|c|}{$U$-value of the window $\left(\mathbf{W} \cdot \mathbf{m}^{-2} \cdot \mathbf{K}^{-1}\right)$} \\
\cline { 2 - 5 } & $\begin{array}{c}U \text {-value of the glazing (triple-glazed) } \\
\left(\mathbf{W} \cdot \mathbf{m}^{-2} \cdot \mathbf{K}^{-1}\right)\end{array}$ & $\begin{array}{c}U \text {-value of the glazing (double-glazed) } \\
\left(\mathbf{W} \cdot \mathbf{m}^{-2} \cdot \mathbf{K}^{-1}\right)\end{array}$ \\
\cline { 2 - 5 } & 0.5 & 0.8 & 1.0 & 1.1 \\
\hline without thermal insulator & $0.78-0.86$ & $0.98-1.06$ & $1.12-1.20$ & $1.18-1.26$ \\
\hline with inserted EPS & $0.77-0.85$ & $0.97-1.05$ & $1.10-1.18$ & $1.17-1.25$ \\
\hline with inserted EPS grey & $0.76-0.84$ & $0.96-1.04$ & $1.10-1.18$ & $1.17-1.25$ \\
\hline with inserted PUR & $0.75-0.83$ & $0.95-1.03$ & $1.09-1.17$ & $1.15-1.23$ \\
\hline with inserted aerogel & $0.74-0.82$ & $0.94-1.02$ & $1.07-1.15$ & $1.14-1.22$ \\
\hline composite frame & $0.74-0.82$ & $0.95-1.02$ & $1.08-1.16$ & $1.15-1.23$ \\
\hline
\end{tabular}

\section{Measurements}

The suitability of the aerogel usage as a part of a window frame has been confirmed by calculations. This theory was also verified by measurement in an accredited laboratory. The measurements were performed for three window frames. The aim of the measurements was to determine the transmission heat loss coefficient of the frames according to the standard CSN EN 12412-2 "Thermal performance of windows, doors and shutters - Determination of thermal transmittance by hot box method - Part 2: Frames". The transmission heat loss coefficient is determined by calculation based on the measured heat flow rate of the parts of measured frame and on the measured heat flow rate of the test equipment and internal and external temperatures. Fig. 5 shows a schema of the test equipment for each measurement. The eight-chamber windows of thickness of the frame of $90 \mathrm{~mm}$ were tested. Three sample frames were measured: 1 - the window frame with the reinforcement without the thermal insulation, 2 - the window frame with aerogel inserted into chambers near to the reinforcement and 3 - the composite window frame without reinforcement and the thermal insulation. The schema of measured frames is shown in Fig. 6 . Also the numerical model was developed for each measured frame and according to the calculation the estimated $U$-value of each frame was determined. Fig. 7 shows the output of software Area 2011 for the frame with inserted aerogel and with reinforcement. The output is a $2 \mathrm{D}$ temperature field. 2D temperature fields for the frame without thermal insulation and with reinforcement and for the composite frame without thermal insulation and reinforcement are very similar.

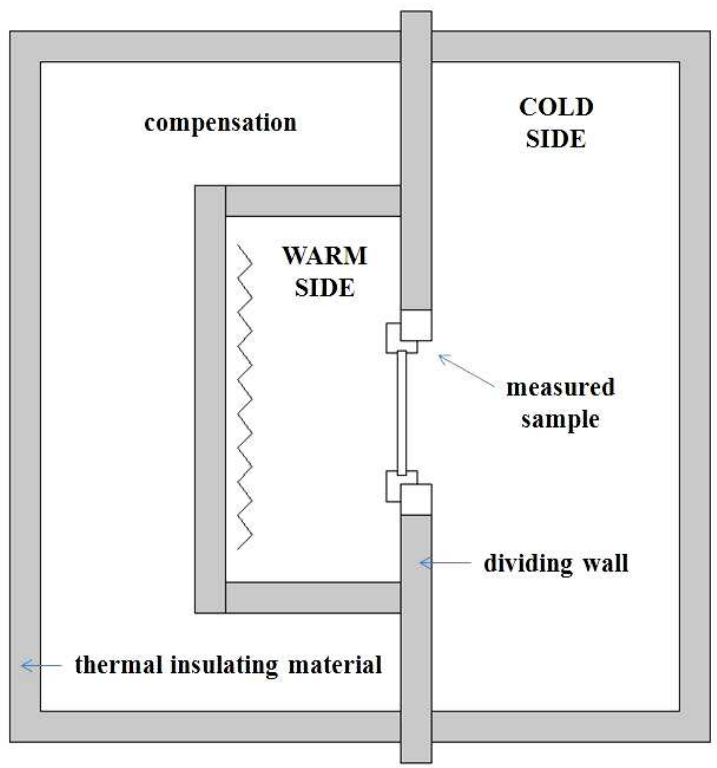

Fig. 5: The schema of the test equipment. 

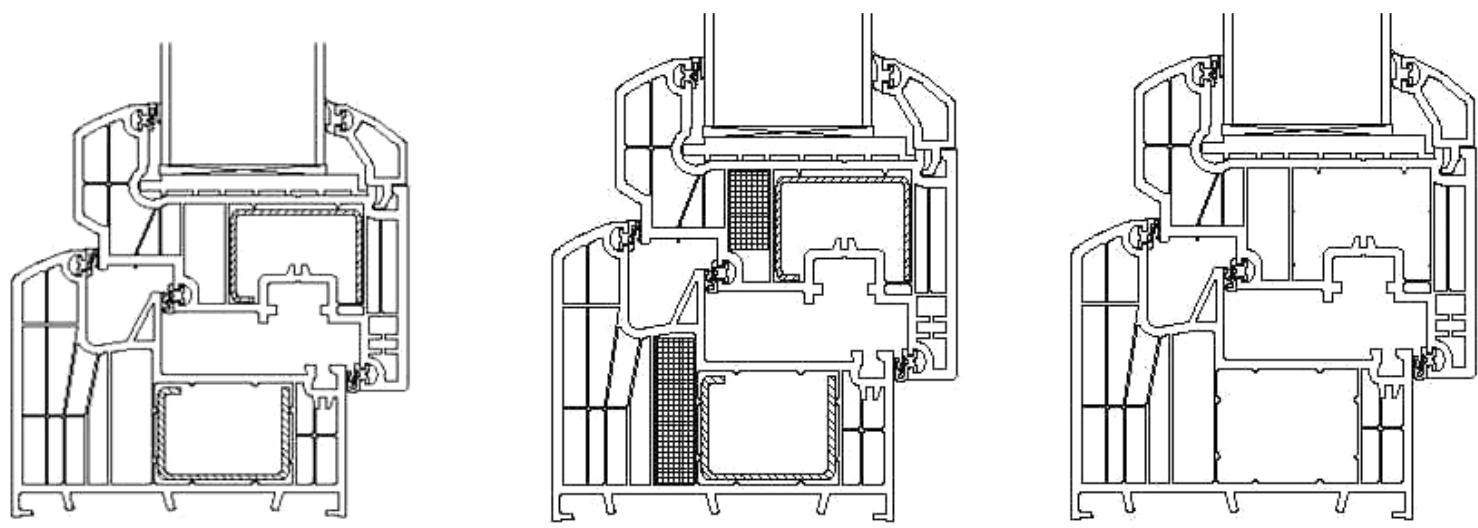

Fig. 6: The schema of measured frames.
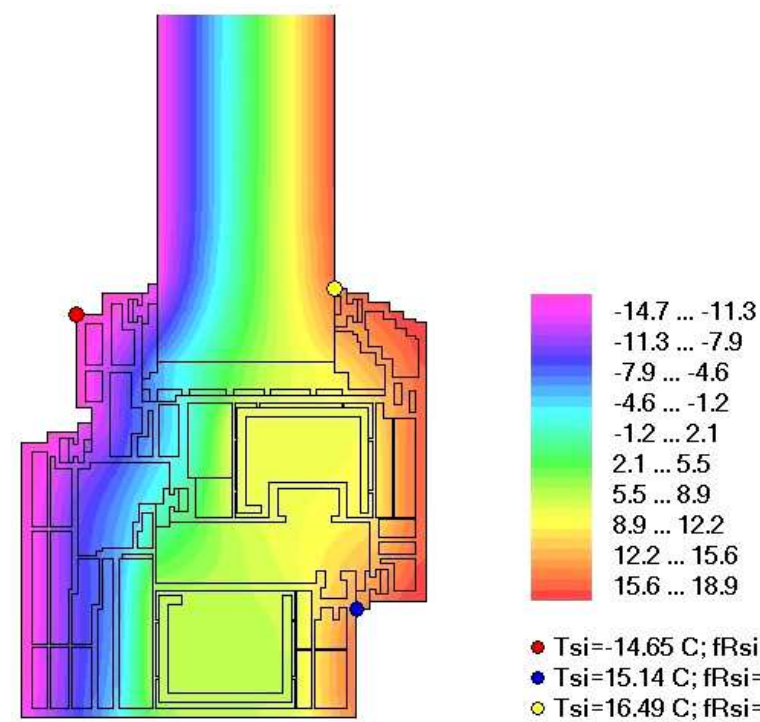

Tsi=-14.65 C; fRsi $=0.990$

- Tsi=15.14 C; fRsi=0.837

Tsi=16.49 C; fRsi $=0.875$

Fig. 7: The temperature field of the frame with inserted aerogel and with reinforcement.

\subsection{Measured and calculated results}

Measured values of the transmission heat loss coefficient of window frames are shown in Table 4. The results of the calculation are shown. The results prove a significant influence of the aerogel inserted into the frame to reduction of the $U$-value of the frame. Although the composite frame has better thermal insulating properties, it is necessary to realize that the production of the composite frame is very expensive. The measurement showed that the reduction of the $U$-value of the frame with inserted aerogel is $0.09 \mathrm{~W} \cdot \mathrm{m}^{-2} \cdot \mathrm{K}^{-1}$. It is a significant improvement of the $U$-value in comparison with the frame without inserted thermal insulation. Significant differences were detected when comparing results of the measurement to the results of calculation. According to the results of calculation, it was expected that the $U$-value of the frame with aerogel is $0.95 \mathrm{~W} \cdot \mathrm{m}^{-2} \cdot \mathrm{K}^{-1}$. According to the measurement the $U$-value is much better, it is $0.81 \mathrm{~W} \cdot \mathrm{m}^{-2} \cdot \mathrm{K}^{-1}$. The difference is probably caused by a simplified model of window frame, which was created as a computational model. However, it is evident that there are not significant differences between the measured and the calculated $U$-value of the frames.

Table 4: Measured and calculated results.

\begin{tabular}{|l|c|c|}
\hline \multirow{2}{*}{ Kind of the frame } & \multicolumn{2}{|c|}{$\boldsymbol{U}$-value of the frame $\boldsymbol{U}_{f}\left(\mathbf{W} \cdot \mathbf{m}^{-2} \cdot \mathbf{K}^{-1}\right)$} \\
\cline { 2 - 3 } & measured value & calculated value \\
\hline $\begin{array}{l}\text { 1. without inserted insulation } \\
\text { and with reinforcement }\end{array}$ & 0.90 & 1.06 \\
\hline $\begin{array}{l}\text { 2. with inserted aerogel } \\
\text { and with reinforcement }\end{array}$ & 0.81 & 0.95 \\
\hline $\begin{array}{l}\text { 3. composite frame without insulation } \\
\text { and reinforcement }\end{array}$ & 0.77 & 0.92 \\
\hline
\end{tabular}




\section{Conclusion}

Due to the energy efficiency of buildings, windows are considered to be an important, but also the most problematic element of the building envelope. It is caused by their $U$-value, which is significantly higher than the $U$-value of other structures of the building envelope. The values of the transmission heat loss coefficient are in the range from about $0.5 \mathrm{~W} \cdot \mathrm{m}^{-2} \cdot \mathrm{K}^{-1}$ to $1.5 \mathrm{~W} \cdot \mathrm{m}^{-2} \cdot \mathrm{K}^{-1}$. Other parts of the building envelope are today designed to have a significant lower $U$-value. For example, the $U$-value of the envelope walls of passive buildings [21] is nowadays about $0.1 \mathrm{~W} \cdot \mathrm{m}^{-2} \cdot \mathrm{K}^{-1}$ or lower. Because windows are the elements of the building envelope with bad thermal insulating properties, they are considered to be a thermal bridge. The negative influence of windows to the energy efficiency of buildings can be minimized by reducing of a windows area in the building envelope. Indeed, windows cannot be excluded from the building envelope. During the windows area design, it is necessary to take into account requirements of the standard CSN 73 0580-1 "Daylighting in buildings Part 1: Basic Requirements". The windows are integral elements of the building envelope. Therefore, the development of them is very important and it is necessary to keep improving thermal insulating properties of windows. It may be achieved by improving of thermal insulating properties of glazing, frame or by using of special warm spacers. In the case of glazing, an improving of its thermal insulating properties is restricted by the thickness of glazing. The quadruple glazed windows have the best thermal insulating properties; however, the using of these kinds of windows is not expected in the future. For their weight and the design of their frame which must support the glazing. Another problem is the reduction of the solar transmittance of quadruple glazed windows. This is related to necessity of designing of larger windows area in the building envelope. Also it is reducing solar gain in winter and it negatively affects a total heat balance of the building.

Other possibility, how to improve thermal insulating properties of windows, is improving of thermal insulating properties of the window frame. The basic frames have only five chambers and they have the reinforcement inside their structure. The thermal insulating materials are inserted into the chambers to reduce the $U$-value of the frame. Finally, the frames without the reinforcement are used. This kind of frame is made of a special composite material. To improve the thermal insulating properties of the window frame, a modern thermal insulating material called aerogel was proposed to use. Aerogel is a solid material based on silicon. It is the material with the lowest density. This material contains more than $95 \%$ of air, the rest is silica. A thermal conductivity of aerogel is very low; therefore it is convenient to use aerogel inside a frame structure. It was suggested to insert aerogel into the chambers of the window frame. According to the results of the calculation, the designed frames were thermal technical assessed. The calculations were done for other kinds of frames - the basic frame without inserted thermal insulation, three kinds of frames with thermal insulation and the composite frame without the reinforcement. Results of these calculations were compared and it showed that the best variant of the frame is the frame of thickness $95 \mathrm{~mm}$. It was proved, that using of composite frames is advantageous in the case of the frame of low thickness.

\section{Acknowledgements}

The work was supported from founds of the Conceptual development of science, research and innovation for 2017 allocated to the VŠB - Technical University of Ostrava by the Ministry of Education, Youth and Sports of the Czech Republic.

\section{References}

[1] CUCE, E. - CUCE, P. M. - WOOD, C. J. - RIFFAT, S. B.: Toward aerogel based thermal superinsulation in buildings. Renewable and Sustainable Energy Reviews, Vol. 34, 2014, pp. 273 299.

[2] MONICA, C. - POPOVICI, C. - NELU-CRISTAN, C.: Experimental and numerical approach of the thermal conductivity of building façade. WSEAS Transactions on Heat and Mass Transfer, Vol. 5, Iss. 3, 2010, pp. $103-112$.

[3] IHARA, T. - GRYNNING, S. - GAO, T. - GUSTAVSEN, A. - JELLE, B. P.: Impact of convection on thermal performance of aerogel granulate glazing systems. Energy and Buildings, Vol. 88, 2015, pp. $165-173$.

[4] WITTWER, V.: Development of aerogel windows. Journal of Non-Crystalline Solids, Vol. 145, Iss. C, 1992 , pp. $233-236$. 
[5] BURATTI, C. - MORETTI, E.: Experimental performance evaluation of aerogel glazing systems. Applied Energy, Vol. 97, 2012, pp. 430 - 437.

[6] GAO, T. - JELLE, B. P. - IHARA, T. - GUSTAVSEN, A.: Insulating glazing units with silica aerogel granules: The impact of particle size. Applied Energy, Vol. 128, 2014, pp. 27 - 34.

[7] DRUEL L, L. - BARDL, R. - VORWERG, W. - BUDTOVA, T.: Starch Aerogels: A Member of the Family of Thermal Superinsulating Materials. Biomacromolecules, Vol. 18, Iss. 12, 2017, pp. 4232 4239, DOI: 10.1021/acs.biomac.7b01272.

[8] KOEBEL, M. - RIGACCI, A. - ACHARD, P.: Aerogel-based thermal superinsulation: An overview. Journal of Sol-Gel Science and Technology, Vol. 63, Iss. 3, 2012, pp. 315 - 339, DOI: 10.1007/s10971-012-2792-9.

[9] SWIMM, K., - REICHENAUER, G. - VIDI, S. - EBERT, H.-P.: Impact of thermal coupling effects of the effective thermal conductivity of aerogels. Journal of Sol-Gel Science and Technology, Vol. 84, Iss. 3, 2017, pp. 466 - 474, DOI: 10.1007/s10971-017-4437-5.

[10]PISAL, A. A. - VENKATESWARA RAO, A.: Development of hedrophobic and optically transparent monolithic silica aerogels for window panel application. Journal of Porous Materials, Vol. 24, Iss. 3, 2017, pp. 685 - 695, DOI: 10.1007/s10934-016-0305-x.

[11]MORETTI, E. - ZINZI, M. - CARNIELO, E. - MERLI, F.: Advanced Polycarbonate Transparent Systems with Aerogel: Preliminary Characterization of Optical and Thermal Properties. Energy Procedia, Vol. 113, 2017, pp. 9 - 16, DOI: 10.1016/j.egypro.2017.04.003.

[12]LV, Y. - HUANG, R. - WU, H. - WANG, S. - ZHOU, X.: Study on Thermal and Optical Properties and Influence Factors of Aerogel Glazing Units. Procedia Engineering. Vol. 205, 2017, pp. 3228 3234, DOI: 10.1016/j.proeng.2017.10.295.

[13] SCHULTZ, J. M. - JENSEN, K. I. - KRISTIANSEN, F. H.: Super insulating aerogel glazing. Solar Energy Materials and Solar Cells, Vol. 89, Iss. 2 - 3, 2005, pp. 275 - 285, DOI: 10.1016/j.solmat. 2005.01.016.

[14]ROOS, A. - KARLSSON, B.: Optical and thermal characterization of multiple glazed windows with low $U$-values. Solar Energy, Vol. 52, Iss. 4, 1994, pp. 315 - 325.

[15] ORAVEC, P.: Windows in buildings - diagnostic of selected properties after time of using. Advanced Materials Research, Vol. 899, 2014, pp. 184 - 187.

[16]KAMENICKY, L. - PALKO, M. - PUSKAR, A.: Diffuse characteristics of window frame gasket system. Advanced Materials Research, Vol. 855, 2013, pp. 134 - 137.

[17]PALKOVA, A. - PALKO, M.: Thermal and moisture problems of wooden windows. Advanced Materials Research, Vol. 899, 2014, pp. 180 - 183.

[18]KAMENICKY, L.: Wooden window structure and its thermos-humid mode. Advanced Materials Research, Vol. 899, 2014, pp. 188 - 192.

[19]KAMENICKY, L. - PALKO, M. - PUSKAR, A. Diffuse Characteristics of Window Frame Gasket System. Advanced Materials Research, Vol. 888, 2013, pp. 134 - 137, DOI: 10.4028/ www.scientific.net/AMR.855.134. 21.

[20]PALKO, M. - PALKOVA, A. - PUSKAR, A.: Analysis of water vapour condensation in gap between casement and window frame of wooden windows. Wood Research, Vol. 57, Iss. 4, 2012, pp. 581 590.

[21] LAHUTA, H. - SKOTNICOVA, I.: Dynamic thermal performance of building structures in experimental lightweight timber-frame passive house. SGEM 2013, Bulgaria, 2013, pp. $403-410$, DOI: 10.5593/SGEM2013/BF6/S26.008. 